\title{
Transdisciplinary research for supporting the inte- gration of ecosystem services into land and water management in the Tarim River Basin, Xinjiang, China
}

\author{
Tuck-Fatt SIEW*, Petra DÖLL \\ Institute of Physical Geography, Goethe University Frankfurt, Altenhöferallee 1, D-60438 Frankfurt am Main, Germany
}

\begin{abstract}
There is a growing need for both science and practice domains to collaboratively and systematically seek knowledge-based strategies for sustainable development. In recent years, transdisciplinary research has emerged as a new approach that enables joint problem solving among scientists and stakeholders in various fields. In this paper, we aim to introduce transdisciplinary research for supporting the integration of the concept of ecosystem services into land and water management in the Tarim River Basin, Xinjiang, Northwest China. While a large number of ecosystem service studies have helped to raise the awareness for the value of nature in China, a number of challenges remain, including an improved understanding of the relationships between ecosystem structure, functions and services, and the interaction of the various ecosystem services. A meaningful valuation of ecosystem services also requires the consideration of their strong spatial heterogeneity. In addition, ways to introduce the concept of ecosystem services into decision-making in China need to be explored. Thus, successful integration of the concept of ecosystem services into actual land and water management requires a broad knowledge base that only a number of scientific disciplines and stakeholders can provide jointly, via a transdisciplinary research process. We regard transdisciplinary research as a recursive process to support adaptive management that includes joint knowledge generation and integration among scientists and stakeholders. System, target, and transformation knowledge are generated and integrated during the process of (1) problem (re)definition, (2) problem analysis and strategy development, and (3) evaluation of the impact of the derived strategy. Methods to support transdisciplinary research comprise participatory modelling (actor-based modelling and Bayesian Networks modelling) and participatory scenario development. Actor-based modelling is a semi-quantitative method that is based on the analysis of problem perspectives of individual stakeholders as depicted in perception graphs. With Bayesian Networks, complex problem fields are modelled probabilistically in a simplified manner, using both quantitative data and qualitative expert judgments. These participatory methods serve to integrate diverse scientific and stakeholder knowledge and to support the generation of actually implementable management strategies for sustainable development. For the purpose of integrating ecosystem services in land and water management in the Tarim River Basin through transdisciplinary research, collaboration among scientists and institutional stakeholders from different sectors including water, agriculture, forestry, and nature conservation is required. The challenge is to adapt methods of transdisciplinary research to socio-cultural conditions in China, particularly regarding ways of communication and decision-making.
\end{abstract}

Keywords: transdisciplinary research; land and water management; ecosystem services

Societal problems such as those encountered in the field of environmental and natural resources management are subject to complexity, uncertainty, change, and imperfection (Bammer, 2005). Due to the interconnectedness of a multitude of scientific and social issues in human-environment systems, sustainable goals can neither be achieved by single scientific disciplines nor single groups of societal actors. Scientists

Received 2011-10-31; accepted 2012-02-22

"Corresponding author: Tuck-Fatt SIEW (E-mail: tuckfatt.siew@em.uni-frankfurt.de) 
from a variety of disciplines need to work in an interdisciplinary manner with a number of practitioners from problem-relevant sectors to seek collaboratively knowledge-based solutions, using new integrative approaches and methods. Such type of joint research involving scientists and stakeholders is called "transdisciplinary research" (Thompson Klein et al., 2001; Hirsch Hadorn et al., 2006). We regard the terms "societal actor", "practitioner" and "stakeholder" as synonyms. In this paper, the term "stakeholder" will be used.

It has to be emphasized that transdisciplinary research is not a new scientific discipline but a specific collaborative and integrative research approach (Wiesmann et al., 2008) that aims at supporting sustainable development (Max-Neef, 2005). It involves the participation of all relevant scientific disciplines and stakeholders across various sectors. The participatory transdisciplinary research process offers an opportunity for social learning towards sustainability (Luks and Siebenhüner, 2007).

The core of transdiciplinary research is joint generation and integration of scientific and stakeholder knowledge (Jahn, 2008). In transdisciplinary research, the relevance of different forms of knowledge, including knowledge from the outside of the scientific domain is recognized (Mobjörk, 2010). Bringing researchers together with stakeholders can help overcome the gap between demand for knowledge and knowledge production (Cronin, 2008). In its effort of tackling real-world problems, transdisciplinary research goes beyond merely improving the implementation of scientific knowledge in practice.

Transdisciplinary research has already been conducted in various problem fields. It was applied to support policy formulation for sustainable agriculture development in Belgium (Vandermeulen and Van Huylenbroeck, 2008), regional planning in Switzerland (Wiek and Walter, 2009), conservation planning in South Africa (Reyer et al., 2010) and Canada (Steventon, 2008), and water management in Sri Lanka (Cain et al., 2003). Adaptive Integrated Water Resources Management as elaborated by UNESCO (2009) can be regarded as transdisciplinary research. To our knowledge, transdisciplinary research has not yet been done in the social-ecological context in China, but Jiang (2009) recognized the value of transdiscipli- nary research and indicated its contribution to the development of sustainable socio-economic strategies in China.

It is state-of-the-art to evaluate strategies for land and water management with respect to social, economic, and ecological aspects. Very often, strategies achieving improved ecological conditions are perceived as having negative economic and social impacts (Millington, 2000). Here, the concept of ecosystem services has the potential to resolve this conflict and to indicate win-win situations in sustainable management without trade-offs between "environment" and “development” (De Groot et al., 2010). Ecosystem services are the goods and services that natural ecosystems provide to humans, e.g. clean water or food (MA, 2005). They are the dividend of humankind's natural capital. The value of the world's ecosystem services certainly exceeds the global gross national product even though the monetization of non-marketed ecosystem services is difficult (Costanza et al., 1997). It is believed that a better development of human societies can be achieved by improved recognition and understanding of ecosystem services (TEEB, 2010), and by integrating the concept of ecosystem services into land and water management.

Thinking in terms of ecosystem services connects the well-being of ecosystems, i.e. ecological conditions, to the well-being of humans, i.e. social and economic conditions. For example, a management measure may decrease soil quality but increase farmer income, and this trade-off would make it difficult to decide rationally if the measure should be taken or not. If the change in soil-related ecosystem services (also in the mediumand long-term future) due to the decreased soil quality could be quantified, then this value would have to be subtracted from the increase of farmer income to determine the total economic effect of the proposed measure. The management measure would only be taken if the increase in farmer income is larger than the decrease in ecosystem services. Thus, "the fundamental purpose of ecosystem services valuation is not to put a price tag on an ecosystem or its components, but to express the effect of a marginal change in the ecosystem services provision in terms of the trade-off rate against other things that people value" (Zhang et al., 2010a).

We envisage that the concept of ecosystem services is useful to support land and water management in arid 
regions like the Tarim River Basin, where water is scarce and ecosystems are fragile. The Tarim River Basin is located in the dry southern part of Xinjiang, Northwest China. During the last decades, the region has suffered from various land- and water-related problems such as desertification, soil salinization, loss of floodplain vegetation and the drying up of Taitema Lake (Shen and Lein, 2005; Xu et al., 2008; Lu et al., 2010; Wu et al., 2010). Much effort has been made by the central and local governments to address these problems. Restricted restoration of floodplain vegetation in the lower reaches of the Tarim River has been achieved, and many technical measures for securing and saving water have been taken (Lu et al., 2010). However, the balance between water for agriculture and water for natural ecosystems remains difficult, and benefits of agricultural water use still need to be optimized. A management system for optimizing basin-wide social, economic, and ecological conditions must be designed and implemented (Shen and Lein, 2005; Lu et al., 2010).

How to include the concept of ecosystem services into practical land and water management? Certainly, knowledge of multiple scientific disciplines and stakeholders pertaining to land and water management as well as ecosystem services has to be integrated. For the management of land and water resources in the Tarim River Basin, extensive knowledge generated by scientists, particularly on natural system components, should be utilized and complemented. To this end, cross-disciplinary and cross-sectoral communication has to be improved (Petts et al., 2006). This is where transdisciplinary research has a role to play, and we hope to perform and scientifically evaluate a transdisciplinary research process in the Tarim River Basin.

In this paper, we aim at introducing transdisciplinary research for supporting the integration of the concept of ecosystem services into land and water management in the Tarim River Basin. Concept and specific methods of transdisciplinary research are described in Section 2. In Section 3, two examples of transdisciplinary research processes are presented. The idea of implementing transdisciplinary research to support sustainable land and water management in the Tarim River Basin is elaborated in Section 4, including the concept of ecosystem services. This paper concludes by highlighting potential benefits and chal- lenges of implementing transdisciplinary research.

\section{Transdisciplinary research}

In the simplest understanding, there is a progression from disciplinary through multidisciplinary and interdisciplinary to transdisciplinary research (Pohl, 2010). As defined by Pohl et al. (2008), multidisciplinary research approaches an issue from the perceptions of a range of disciplines. Each discipline works in a self-contained manner with little cross-fertilisation among disciplines or synergy in the outcomes. Interdisciplinary research refers to a form of coordinated and integration-oriented collaboration between researchers from different disciplines. Transdisciplinary research refers to interdisciplinary research with additional collaboration of multiple non-scientific institutions (stakeholders).

Transdisciplinary research is problem-based. It focuses on a problem as a whole, rather than just looking at parts of the problem. By considering a problem in a systemic way, the interrelationships of all relevant issues can be better understood, including the deliberation, research and development about why and how contested practices and institutions have to be changed (Hirsch Hadorn et al., 2006). Transdisciplinary research is appropriate to deal with complex problem fields that are characterized by:

- Societal relevance;

- Interactions between humans and environment;

- Significant uncertainties, ignorance or imperfect evidence;

- Disagreement about the nature of the problem;

- Existence of knowledge outside of academia;

- Important trade-offs among various management options;

- The need for joint action of a large number of stakeholders with differing problem perceptions, values and goals (e.g. industry, farmers, water suppliers and environmental agencies).

Up to now, a coherent theory and methodology of transdisciplinary research has not yet been proposed in the literature. It is argued that it is necessary to learn about transdisciplinary research from specific projects that serve as paradigms in understanding and structuring problems, which then can give rise to formalization (Pohl and Hirsch Hadorn, 2008). In this regard, transdisciplinary research needs to be designed care- 
fully (Max-Neef, 2005). We present our concept of transdisciplinary research as well as methods that we regard as particularly useful for knowledge generation and integration in the next section.

\subsection{Concept of transdisciplinary research}

Our concept of transdisciplinary research merges two different concepts: the definition of transdisciplinary research as a recursive process (Pohl and Hirsch Hadorn, 2007) and the spiral model of adaptive integrated water resources management as conceptualized by UNESCO (2009). We regard transdisciplinary research as a recursive process to support adaptive management that includes joint knowledge generation and integration among scientists and stakeholders. Each cycle of the transdisciplinary process consists of five steps (Fig. 1):

(1) Problem (re)definition (framing of the problem taking into account different perceptions of scientists and stakeholders as well as the interests and goals of relevant stakeholders);

(2) Problem analysis and strategy development;

(3) Implementation (strategies are implemented by responsible institutions);

(4) Monitoring (implemented strategies and their outcomes are monitored);

(5) Evaluation (information derived from monitoring is assessed).

In transdisciplinary research, three different types of knowledge need to be generated and integrated (CASS/Proclim, 1997): (1) system knowledge, (2) target knowledge, and (3) transformation knowledge. Scientists and stakeholders jointly generate this knowledge and integrate it in steps 1, 2 and 5 (Fig. 1). System knowledge is required by stakeholders to gain an understanding about how the human-environment system works. Target knowledge is required to understand the goals of the diverse actors. Transformation knowledge refers to knowledge about how to achieve (common) goals. Both target and transformation knowledge are required in particular to identify actually implementable strategies, but are traditionally neglected, which is often the case in most interdisciplinary research. Being an iterative process, the problem can be redefined based on new data and knowledge, and new manage ment strategies can also be derived as knowledge about system, goals, and transformation process is updated. Throughout the "experience-knowledge-action" process

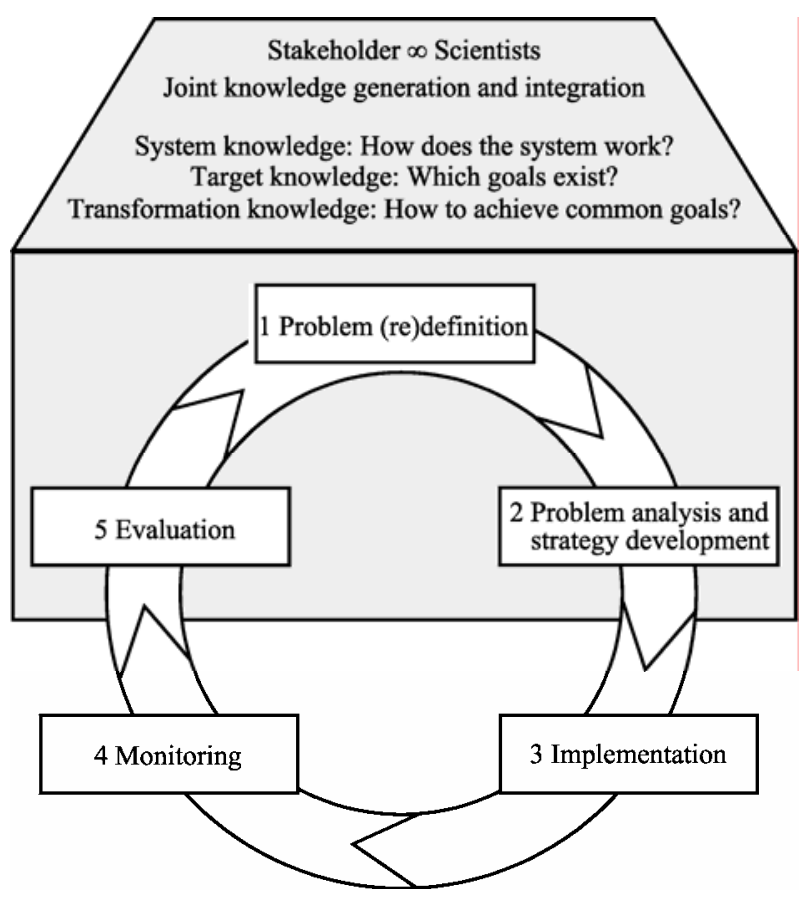

Fig. 1 Transdisciplinary research as a recursive process to support adaptive management, with joint knowledge generation by stakeholders and scientists

(Medema et al., 2008), the knowledge and implementation gaps can be identified (Jakeman et al., 2006).

Based on the role and activity of stakeholders in the process, two types of transdisciplinary research can be distinguished, consulting transdisciplinary research and participatory transdisciplinary research (Mobjörk, 2010). In consulting transdisciplinary research, the stakeholders have a role in commenting the research conducted. Scientists bear stakeholder perspectives in mind during the research process. In participatory transdisciplinary research, stakeholders take a much more active role in knowledge generation. Knowledge of stakeholders and scientists are equally valued for knowledge integration. We aim at participatory transdisciplinary research due to its higher potential for broad knowledge integration, and because participatory processes have been shown to lead to a higher quality of decision-making (Beierle, 2002; Sultana and Abeyasekera, 2007).

\subsection{Methods of transdisciplinary research}

Transdisciplinary research processes must be supported by suitable methods. These methods should be able to grasp complexity, to deal with uncertainty and to take into account the diversity of problem perceptions of the actors from inside and outside of academia 
(Mobjörk, 2010). They should enable knowledge generation, exchange, and integration as well as mutual learning and result in implementable problem solutions. The choice of methods depends on the problem field, the socio-cultural context, the goal of the process, the type and number of participants, and the available capacity. Transdisciplinary research methods we prefer include:

- Interviews with stakeholders and experts;

- Guided discussions (in workshops);

- Participatory modelling (e.g. systems modelling, actor-based modelling and Bayesian Networks);

- Participatory scenario development.

In the following section, we present three different but complementary methods, actor-based modelling, Bayesian Networks and scenario development which fulfil the requirements for transdisciplinary methods. We plan to apply these three methods in the Tarim River transdisciplinary research process.

\subsubsection{Actor-based modelling}

Actor-based modelling is a semi-quantitative modelling approach that consists of three steps:

(1) Actor modelling: modelling of the problem perspectives of the most relevant actors by semi-quantitative perception graphs, including the determination of actions that would lead to optimum goal achievement.

(2) Modelling of actions: inferring the actions these actors will take (e.g. "reduce pesticide use") under specific scenario conditions.

(3) Modelling of factors: estimating the changes in factors (e.g. "cotton production") resulting from these actions.

Actor-based modelling supports problem (re)definition as well as problem analysis and strategy development in our transdisciplinary research process (Fig. 1).

Actor modelling is performed using the software DANA (www.dana.actoranalysis.com; Bots et al., 2007). An example of a perception graph generated using the software is illustrated in Fig. 2. A perception graph is a semi-quantitative directed acyclic graph (causal network) that depicts the problem perspectives (including goals, influence factors, actions, and prospects and how they are related to each other) of a stakeholder (actor). All boxes and arrows are quantified using a seven-point scale. Figure 2 shows the problem perspectives of an environmental protection agency in a fictitious case in the problem field of wa-

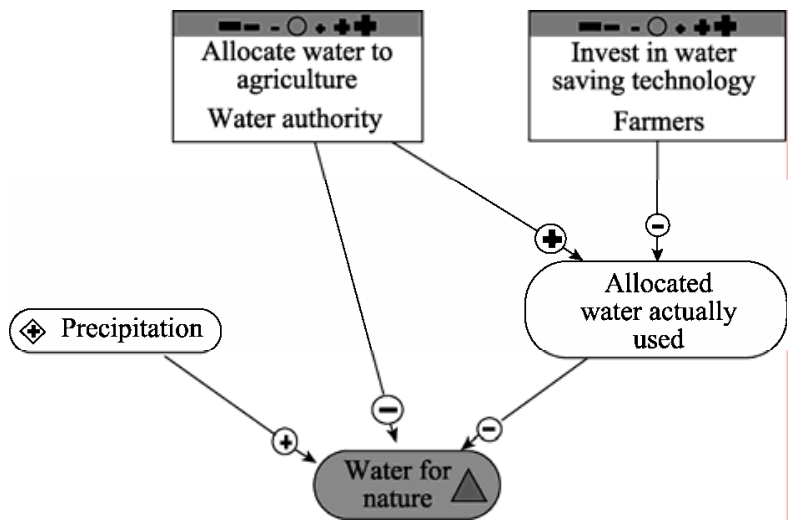

Fig. 2 An example of a simple perception graph depicting the problem perspectives of an environmental protection organization in a fictitious case of the problem field water management in arid regions. The arrows qualified with $€$ or $\odot$ sign in different sizes depict the intensity of the correlation between each element of the goal factors, influence factors, actions, and prospects

ter management in arid regions.

The goal factor 'water for nature' is placed at the bottom of the graph (Fig. 2). The upward triangle $\Delta$ means that the goal of the environmental protection agency is to increase water for nature. According to the perception of the actor, the goal factor is strongly influenced by the factor 'allocated water actually used', which is influenced by both actions and has an influence on the goal. The arrows qualified by $\oplus$ or $\Theta$ signs in different sizes depict the intensity of the positive or negative correlation. This factor is perceived to be impacted by two actions, 'allocate water to agriculture' and 'invest in water saving technology', which, from the perspective of the environmental protection agency, can be taken by water authority and farmers, respectively (top of the graph). The change level of each action is described with a seven-point scale $(\boldsymbol{-}-\mathbf{0}+\boldsymbol{+}+$, i.e. from strong decrease $\mathbf{-}$ via unchanged $\_$to strong increase $\$$ ). The factor 'precipitation' is seen here as a 'prospect' with an expected increasing trend, symbolized with ${ }^{+}$. 'Prospect' is external development that cannot be influenced by actions of stakeholders included in the actor analysis. The perception graph in Fig. 2 expresses the perception that water allocation to agriculture by the water authority strongly decreases water for nature, and that farmers can increase water for nature somewhat by investing in water saving technology. Increasing precipitation will also lead to somewhat more water for nature. 
Based on the perception graph, the actions that are optimal from the perspective of individual actors are computed by DANA. In some applications, actor-based modelling might stop at this point. While in other applications, the individual perception graphs may be combined and integrated into a single perception graph (with or without goals) that tries to depict all relevant factors, actions, and prospects. Optimal actions as determined from the individual perception graphs may be implemented in the combined graph, and the impact of these actions on factors of interest can be computed in a semi-quantitative manner.

Actor-based modelling can be considered as a type of agent-based modelling, which allows the representation of the complex dynamics of human-technology-environment systems and is particularly suitable for participatory approaches (Pahl-Wostl, 2005). In terms of the characteristics of agent-based modelling proposed by Hare and Deadman (2004), actor-based modelling focuses on the detailed characterization of the specific problem perception of each agent (societal actor) which forms the basis for the computation of actions. In actor-based modelling, the number of actors is small (about 15-20). Actors are not individuals but institutions or groups (e.g. "water suppliers" or "consumers"). Social interactions are modelled in a very simple manner, and there is no feedback of the development of factors to the actions. Nevertheless, feedbacks are considered throughout transdisciplinary research processes. Actor-based modelling has been used in participatory settings in the framework of social-ecological research on pharmaceuticals in drinking water (Titz and Döll, 2009) and mobile organic substances in surface waters (Döll and Döll, 2008).

\subsubsection{Bayesian Networks}

Semi-quantitative actor-based modelling is suitable for very broad problem fields, where the analysis of (conflicting) problem perceptions is important for identifying sustainable development paths. In comparison, Bayesian Networks are suited for integrated quantitative analysis of complex systems where the causal links can be described probabilistically and where knowledge integration and a joint problem definition is the main goal. Like the perception graphs in actor-based modelling, Bayesian Networks are directed acyclic graphs (causal networks). The "boxes" are discrete states of the factors relevant for the problem under consideration. And the causal links are expressed as conditional probability tables (CPT). Thus, the probabilities for a discrete state of the goal factor can be computed as a result of various scenarios (e.g. of land and water management). In so-called Bayesian Decision Networks, goals can be expressed quantitatively as utilities, like it is done in actor-modelling using a semi-quantitative description (Steward-Koster et al., 2010).

Bayesian Networks have been used in participatory settings to support integrated land and water management and planning both in industrialized/western (Bromley et al., 2005) and developing/non-western countries (Cain et al., 2003). In their review of tools for integrating stakeholder knowledge and values in natural resources management and research, Lynam et al. (2007) state that Bayesian Networks serve to simplify complex systems through key variables and their relationships, to elicit knowledge, and to encourage communication and learning among different stakeholders. Besides, they enable the expression and understanding of uncertainty. A number of commercial Bayesian Networks softwares are available. NETICA is a widely used Bayesian Networks development program (www.norsys.com) for a wide range of applications. However, most of them are not related to transdisciplinary research. Although NETICA has been applied at various Chinese universities, none of the more than 300 non-academic clients is known to be from China (www.norsys.com/about_us.htm). Similar to actor-based modelling, Bayesian Networks is adopted to support problem (re)definition as well as problem analysis and strategies development in transdisciplinary research process (Fig. 1).

\subsubsection{Scenario development and analysis}

Scenarios are plausible and consistent descriptions of how the future may unfold. They describe a sequence of future events considering the most important interrelationships of the system components, using if-then statements. Scenarios are not forecasts or predictions (Schwartz, 1998). They cannot be characterized by probabilities because the described systems are too complex or too little understood for prediction to be meaningful. According to Bishop et al. (2007), it is important to think deeply and creatively about the future, or else we run the risk of being surprised and 
unprepared. To be prepared for an uncertain future, it is useful to derive a number of scenarios that encompass a large range of possible futures. For sustainability-oriented land and water management under uncertainty, scenarios of the future are indispensable as they are required for assessing sustainability: will a certain decision made today turn out to be a good decision in diverse futures?

There are different types of scenarios. A scenario can be a qualitative (i.e. description through symbols and words, e.g. storylines), quantitative (i.e. description through numerical values, which are computed using mathematical models), or qualitative-quantitative (the quantification of driving forces and other inputs in mathematical models is derived from storylines, while the models compute indicator values). Scenario analysis starts with the definition of a problem and is followed by scenario development. Depending on specific scenario methods, a number of reference scenarios may be defined first, and then the impact of interventions (decisions) in these different futures can be evaluated. While scenarios can be developed by scientists alone, active participation of stakeholders is recommended in selected steps.

Scenario development is applied in many contexts, in particular to support strategic planning in businesses and to deal with global change, especially environmental change (e.g. scenarios of future greenhouse gas emissions or future water demand). Within a transdisciplinary research process, scenario development and analysis is done specifically to support the development of strategies, in the step problem analysis and strategy development in Fig. 1.

\section{Examples of transdisciplinary research}

We provide two examples from the co-author's own experience with transdisciplinary work. The first example is selected even though the research approach was rather interdisciplinary, with some aspects of consulting transdisciplinary research. However, the problem field is land and water management in a semi-arid region suffering from water scarcity, a problem field very relevant to arid land. The second example represents a participatory transdisciplinary research process related to water pollution.

\subsection{Sustainable land and water management in the semi-arid northeast of Brazil}

To support sustainability-oriented regional planning in two federal states in the semi-arid northeast of Brazil, Piauí and Ceará, the Brazilian-German joint program WAVES (Water Availability and Vulnerability of Ecosystems and Society in the Northeast of Northwest Brazil focused on the interrelation between climate variability and change, water resources and use, agriculture, and migration (Gaiser et al., 2003). Integrated qualitative-quantitative scenarios of regional development in these federal states were developed by a scenario group involving scientists from multiple disciplines. Various numerical models were developed, including a hydrological model, a water use model (Döll and Hauschild, 2002), an agricultural yield model and agro-economic model, and a migration model. These models were coupled to form an integrated model that was used to quantify integrated scenarios (Döll and Krol, 2002). Model input, i.e. the driving forces of development, was guided by qualitative scenarios in the form of storylines. Two reference scenarios were developed which served as the background for testing the impact of specific management interventions such as dam construction, water pricing or the introduction of high-yield cashew varieties. The two reference scenarios were designed by first studying the historic development and current trends, with each scenario carrying into the future a different trend. Reference scenario "Decentralisation-Integrated Rural Development" takes up the strengthening of regional centers, for example by the establishment of higher education institutions outside the capital. For the reference scenario "Coastal Boom and Cash Crops", the trend of increased cash crop production, efforts to promote tourism along the coast, and the fast economic development in the metropolitan areas of Fortaleza (the capital of Ceará) was carried on (Döll and Krol, 2002).

In WAVES, the research became interdisciplinary mainly due to the task of coupling disciplinary models and, even more so, due to joint scenario development by researchers from various disciplines. Consulting transdisciplinarity was achieved by interacting in diverse ways with stakeholders within disciplinary subprojects and three so-called policy workshops with representatives of various planning agencies of Ceará. 
In these workshops, scenario assumptions were discussed and refined. Additionally, interesting policy measures (interventions) were defined. The impacts of the measures were then computed by the integrated model (Döll and Krol, 2002).

\subsection{Mobile organic xenobiotics in surface waters of Hesse, Germany}

In the European Union, 30,000 different chemical substances are produced in an amount larger than one ton per year. Sufficient eco-toxicological analyses are available only for a small fraction of them. This is in particular true for mobile organic xenobiotics (MOX), substances that are highly water soluble but poorly degradable by physico-chemical or biological processes like those occurring in waste water treatment plants. MOX are included in everyday products and get into surface water by use and disposal via entry pathways in quantities that are not well known. Some MOX have been shown to be biologically active in trace concentrations and thus dangerous for aquatic ecosystems (Oehlmann et al., 2006). However, given the large number of substances and the difficulty of comprehensive toxicity tests, it is impossible to assess the risk of all potentially harmful substances at the environmentally relevant concentration in the range of nanograms to micrograms. Therefore, in the framework of the transdisciplinary research project INTAFERE (www. intafere.de), an alternative type of risk assessment was explored. The goal was to develop an approach for a societal decision-making process that is based on the knowledge of exposure to and environmental impact of selected MOX.

In INTAFERE, scientists from the disciplines environmental chemistry, aquatic ecotoxicology, mathematics, and geography collaborated with representatives of 10 societal stakeholders. These stakeholders included manufacturers and processors of selected MOX, a non-governmental environmental organization, a waste water treatment company, a regional water supplier, the regional water authority, and the German environmental protection agency. Problem structuring was done following the Driver-PressureState-Impact-Response approach of the European Environment Agency (EEA, 2001). To quantify the future development of the drivers of MOX emissions into the environment, problem perceptions of the actors were elicited in interviews and during workshops. The method of actor-based modelling was developed to derive semi-quantitative scenarios of future actor behavior and the development of factors like MOX production and water treatment efficiency. These scenarios were used as input for a regional emissions and transport model, which was developed using MOX measurements in Hesse that were performed within INTAFERE. The resulting concentrations of the MOX considered were evaluated with respect to their ecological impacts based on ecological field and laboratory experiments. Altogether, four workshops with stakeholders took place within a three-year period. In a scenario workshop, two groups of stakeholders that were complemented by one scientist each developed alternative qualitative scenarios of the future of MOX in 2030. In another workshop the quantitative scenarios of MOX concentrations in surface water together with the ecological information was discussed.

At the end of the participatory transdisciplinary research process of INTAFERE, scientists and stakeholders could agree on certain elements for an alternative risk assessment. For example a stronger implementation of the precautionary principle under the conditions of uncertainty and even ignorance in the problem field, or the introduction of ecotoxicological tests with substance mixes (Keil and Stieß, 2007). A complete alternative risk assessment procedure could not be developed. The transdisciplinary research process was evaluated by a written survey of stakeholder opinions as well as through discussion among the scientists. We found out that the combination of actor-based modelling and scenario development enhanced the knowledge of both stakeholders and scientists about the investigated problem fields, in particular about the interaction between humans and the environment. Stakeholders appreciated that actor modelling made the different problem perceptions of the stakeholders transparent to the other stakeholders (and the scientists), thus also enriching scenario development. The development of qualitative scenarios by the stakeholders enabled them exploring how the complex problem field could develop in the future. Stakeholders expressed that it was valuable for them to recognise different options for action under variable conditions, to recognise their dependency on other stakeholders' actions, and to realise stakeholders' influence on the emergence of as well as the answer to the problem. 


\section{Transdisciplinary research to support sustainable land and water man- agement in the Tarim River Basin}

\subsection{Current situation of land and water manage- ment in the Tarim River Basin}

The Tarim River Basin is one of the largest inland basins in the world. The main-stem Tarim River is fed by snow and glacier melting coming from its three major tributaries, i.e. Aksu, Hotan, and Yarkant rivers. The Tarim River Basin covers a total area of $1.06 \times 10^{6} \mathrm{~km}^{2}$, which is $63.9 \%$ of the total area of Xinjiang and $11.1 \%$ of the total area of China. The areas of mountains, plains and deserts are $47.3 \%, 21.6 \%$ and $31.1 \%$ of the basin area, respectively (Lu et al., 2010). Since 1980, the population in the Tarim River Basin has increased rapidly, mainly due to in-migration, from about $6 \times 10^{6}$ to more than $9 \times 10^{6}$ in 2008. Extensive natural areas were replaced by (mostly irrigated) cropland and urban areas (Wu et al., 2010). Although occupying only a small portion of the total land area, irrigation agriculture has lead to large-scale exploitation of water resources.

Water use for irrigation is especially intensive along the tributaries of the Tarim River and its upper reaches. Along the tributaries, the volume of water used for irrigating one hectare of cultivated land is 15,000$22,500 \mathrm{~m}^{3}$ as large volumes are required to leach salt before the growing season starts (Jiang et al., 2005). Based on river discharge data for the Aksu-Tarim river at a station $20 \mathrm{~km}$ north of Aksu (upstream of major water use) and the station Aral (downstream of major water use), consumptive water in the interstation area increased from $1.8 \mathrm{~km}^{3}$ in 1965 to $4.8 \mathrm{~km}^{3}$ in 2005 (Tang and Deng, 2010). At the upstream station, glacier melting has lead to an increasing trend of discharge, while the downstream station shows a decreasing trend due to the strongly increased water use. According to Thevs (2011), the increased use of water was attributable to the expansion of irrigation cropland along Aksu and Tarim River (by 26\% between 2000 and 2008), mostly cotton plantations in Aksu prefecture and within the Xinjiang Production and Construction Corps. Since 1989, the amount of water use for agricultural purposes along the Aksu tributary has exceeded the proposed water allocation quota, and thus resulted in a lower than required release of water into the Tarim River (Thevs, 2011).

Exploitation of land and water resources in the Tarim River Basin has degraded local hydrological, climatic and ecological conditions (Wu et al., 2010). Negative impacts are very strong in the middle and lower parts of the Tarim River (Jiang et al., 2005; Shen and Lein, 2005; Xu et al., 2005; Xu et al., 2008; Lu et al., 2010; Wu et al. 2010). Major problems include severe destruction of natural riparian vegetation (the so-called 'Green Corridor' located in the middle and lower reaches of the river, lake drying and water quality deterioration due to mineralization, increasing expansion of desertification and frequent occurrence of natural disasters such as strong wind and sand storms, and destruction of biological diversity including the serious declination of the populations of some animal species (Xu et al., 2008; Wu et al., 2010). The dramatic reduction of water quantity and the deterioration of water quality have resulted out-migration of population from the lower reaches of the Tarim River (Jiang et al., 2005). Xu et al. (2008) argued that these negative effects are attributable also to the construction of reservoirs for local agriculture in the lower reaches.

These environmental problems have gained increasing attention at national as well as international levels. In order to achieve a balance between economic development and environmental protection, various measures have been taken by the Chinese central and local governments to address land and water-related problems since the last two decades. These measures include water transfer from Bosten Lake to Taitema Lake through artificial water channels, the introduction of water saving technology for improving irrigation water use efficiency (e.g. drip irrigation), and the maintenance of river channel as well as water pricing and a pilot project of setting up community-based water management organisations (water user associations). Since 2001, the Chinese government has invested about $1.07 \times 10^{10} \mathrm{RMB}$ yuan mainly in engineering projects under the Integrated Environment Restoration Plan in the Tarim Basin (Lu et al., 2010). However, much effort is still needed in terms of strengthening the institutions and governance of water resources management in the Tarim River Basin (Lu et al., 2010).

In 1992, the local government established the Tarim 
Basin Management Committee and Management Bureau of the Tarim Basin with the support from the World Bank first phase project 'Tarim I' (World Bank, 2006). In 1997, these institutions were strengthened and the Tarim Basin Management Committee was reformed according to the Management Regulations for Water Resources of the Tarim River Basin enacted in 1997 (revised in 2005), and the Tarim Basin Water Resources Commission (TBWRC) was established. This effort was supported by the World Bank second phase project 'Tarim II'. The TBWRC is responsible mainly for strategic decision-making on water allocation in the Basin. The technical program of the Commission is undertaken by the Tarim Basin Management Bureau, who carries a coordinator role in basin-wide water management (i.e. the basin of the mainstream Tarim River). However, the Management Bureau lacks institutional capacity and power to effectively implement integrated land and water resources management (Lu et al., 2010; Zhang et al., 2010b). There is disagreement between the Management $\mathrm{Bu}-$ reau and water management institutions at the prefecture and county levels. As a result, it is difficult to implement a coordinated allocation of water resources in the upper, middle, and lower reaches of the Tarim River (Lu et al., 2010).

\subsection{The concept of ecosystem services as a means to support sustainable land and water man- agement}

Ecosystem services are the direct or indirect contributions of ecosystems to human well-being (TEEB, 2010). The links are the flows of value to human societies as a result of the state and quantity of natural capital. Natural capital includes the diversity of species and genes of individual plants and animals as well as ecosystems such as forests and wetlands. From an economic point of view, the flows of ecosystem services can be seen as the 'dividend' that society receives from natural capital. Maintaining stocks of natural capital allows the sustained provision of future flows of ecosystem services and thereby helps to ensure enduring human well-being (TEEB, 2010).

The concept of ecosystem services has been mainstreamed by the UN Millennium Ecosystem Assessment (2005) and the Economics of Ecosystems and
Biodiversity (TEEB, 2010). The TEEB study was initiated by G8+5 countries (including China) in Potsdam, Germany in 2007. TEEB aims at showing how economic concepts and tools can help equip society with the means to incorporate ecosystem services into decision-making at all levels, thus supporting sustainable development.

Ecosystem services are defined in four categories (TEEB, 2010):

- Provisioning services: providing water, food, raw materials, and medicinal resources.

- Cultural services: providing non-material benefits to people related to recreation and tourism, spiritual experiences, aesthetic appreciation, and sense of belonging.

- Regulating services: regulating local climate and air quality, moderating extreme events, waste water treatment, erosion prevention, and maintenance of soil fertility.

- Supporting services: providing habitats for plants and animals, and maintaining genetic diversity.

Each ecosystem service provides a number of related ecosystem services (i.e. a bundle of ecosystem services). Land and water management can be guided by the aim to optimize the bundle of ecosystem services, thus maximizing total ecosystem services. The optimal ecosystem services bundle is neither provided by natural ecosystems or intensively used croplands. Total ecosystem services can be better increased by multi-functional land use instead of a single-function land use (De Groot et al., 2010). In multifunctional land use, food provision ecosystem service is somewhat lower as compared to intensive agriculture land use, but the total ecosystem services are much higher as ecosystem services like water flow and quality regulation, air quality regulation, and maintenance of genetic diversity are much higher. The photos in Fig. 3 associate these ideas with different land use types in the Tarim River Basin.

The concept of ecosystem services that integrates social, economic, and ecological perspectives is important for supporting the development of policies and instruments for ecosystem management. The concerns raised are about the arbitrary application of the term 'ecosystem services' in scientific studies as well as the 


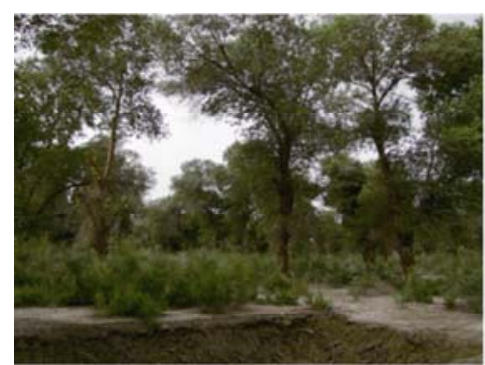

(a) Natural ecosystem

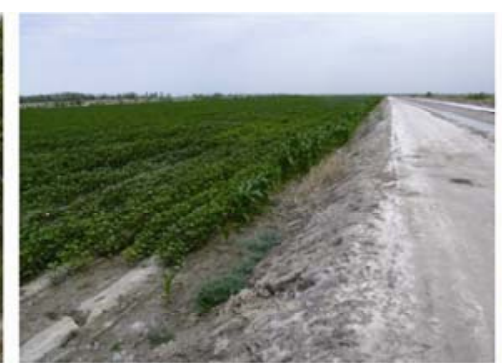

(b) Intensive cropland

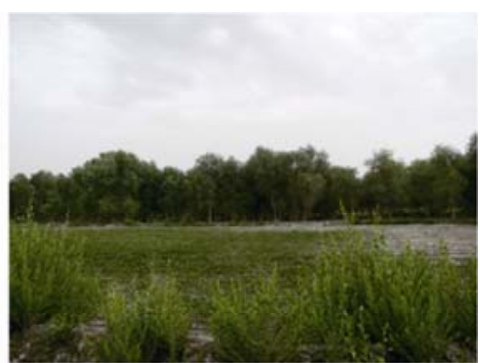

(c) Cropland with natural ecosystem

Fig. 3 Impact of land use and land cover types as well as their management intensities on the provision of ecosystem services. (a) Forest ecosystem with natural vegetation Populus euphratica and Tamarix spp. (b) Intensive cropland cultivated with cotton plant. (c) Mixed land cover types with Populus euphratica (background), cotton (middle), and shrub (foreground), with higher total ecosystem services than $a$ and $b$.

diversity of approaches and methods used in ecosystem service assessments (Seppelt et al., 2011a). According to Seppelt et al. (2011a), ecosystem service research should include (1) the translation of ecosystem functions into ecosystem services, (2) trade-offs between ecosystem services, (3) off-site effects of local decisions on distant ecosystem services, and (4) stakeholder involvement to relate ecosystem function to human well-being. Getting stakeholder involved in ecosystem services research will be an essential step for gaining a wider picture, ground-truthing academic possibilities and providing an estimate of stakeholder preferences for management measures (Seppelt et al., 2011a). Seppelt et al. (2011b) have proposed a blueprint for a standardized reporting on ecosystem services studies. Of the total 152 papers reviewed by Seppelt et al. (2011a), 22 papers reported studies conducted in China.

There have been more than 200 published ecosystem services studies in China, with a focus on forest ecosystems, but a number of remaining challenges were noted (Tian, 2008; Zhang et al., 2010a). These include (1) a lack of the studies on the relationships among certain ecosystem structures, process, functions and services, (2) the application of foreign valuation standards instead of specifically Chinese ones, (3) large differences in evaluated ecosystem service types, (4) inadequate consideration of the spatial heterogeneity of ecosystem functions, and (5) controversies about the actual applicability of the concept of ecosystem serviced in management (Zhang et al., 2010a). Studies on ecosystem services valuation have greatly raised public awareness about the value of nature in China, ranging from individual to government level. However, the accessibility and application of ecosystem services valuation in decision-making need to be enhanced (Zhang et al., 2010a). With specific reference to the Tarim River Basin, Huang et al. (2010) concluded in their study that artificial (e.g. farmland) and natural ecosystems are equally important and their combined capacity for providing various ecosystem services should be considered and balanced.

To show the value of ecosystem services in different ecosystems, Xu et al. (2008) investigated the impact of dam removal and water transfer on the lower reaches of the Tarim River. These measures led to a certain restoration of the natural capital and thereby the provision of ecosystem services. The elevation of the ground water level at the lower reaches had contributed to the improvement of the quantity and quality of indigenous plant species (including $P$. euphratica and Tamarix spp.) along the Tarim River in the lower reaches between Daxihaizi Reservoir and Taitema Lake. The rehabilitated riparian natural ecosystem had an effect on moderating wind-sand hazards, which together with the increase of cultivable land, resulted in the increase in local agriculture production (by $128 \%$ based on the investigation conducted at a state farm at the lower reaches). Additionally, the improvement of grassland condition was also claimed to be beneficial to animal husbandry.

\subsection{Implementation of transdisciplinary research in the Tarim River Basin}

Implementation of transdisciplinary research requires participative collaboration among multiple disciplinary scientists as well as stakeholders throughout the process. In the Tarim River Basin, natural scientists play a particular active and important role in supporting the management of land and water resources. Their expertise is often called for to analyse the current 
situation and to recommend strategies to deal with the problems. For land and water management at the basin level, we suggest intensifying interdisciplinary collaboration among natural scientists and engineers. Moreover, economists and social scientists should become more involved. Then, increased synergies of scientific knowledge can be obtained.

Throughout the transdisciplinary research process, stakeholders of different institutional levels and professions must also be involved. Taking into account their experience, knowledge, perspectives and values will improve the problem understanding as well as the identification of realistic and realizable sustainable land and water management strategies. To illustrate the success of stakeholder participation in other countries: In most of the 239 case studies of stakeholder participation in environmental management in the USA, participation improved the quality of decisions by adding new information, ideas and analysis, and by achieving win-win solutions (Beierle, 2002). In 36 cases of fisheries management in Bangladesh, there was greater uptake of conservation measures and fewer conflicts between stakeholders in cases with participation as compared to cases without participation (Sultana and Abeyasekera, 2007). To achieve the involvement of all relevant stakeholders in the Tarim River Basin, a strategic stakeholder is required. The strategic stakeholder must be characterized by an interest in land and water management and by the will, influence, and power to engage other relevant stakeholders.

Transdisciplinary knowledge generation and integration requires a careful design of the participatory process. In the German-Chinese SuMaRio project (Sustainable Management of River Oases along the Tarim River, www.sumario.de), we plan to design and perform a transdisciplinary research process on integrating ecosystem services into land and water management in the Tarim Basin. In particular, we will investigate how existing methods of transdisciplinary research can be adapted to the socio-cultural context of the Tarim River Basin so that they are appropriate for the communication styles and ways of decision-making in China.

According to our preliminary plan, the SuMaRiO transdisciplinary process (designed as 'stakeholder dialogue’) will likely consist of stakeholder interviews and five workshops distributed over a period of approxi- mately 30 months. Interviews will be conducted individually with workshop participants, other experts, or representatives of relevant stakeholders. We foresee 15-20 interview partners who will take part ideally throughout the stakeholder dialogue process. In the interviews, the problem perceptions of the stakeholders will be elicited. Using actor modelling, the problem perceptions will be analyzed and communicated among the stakeholders during the workshops. Actor-based modelling and Bayesian Networks will be applied to integrate stakeholder and scientific knowledge (including research results of the SuMaRiO project). Appropriate ecosystem services indicators for sustainable land and water management in the Tarim River Basin will also be jointly identified through workshops. Finally, the transdisciplinary research process will be evaluated in terms of successful knowledge integration and social learning. Getting stakeholders involved in the planned transdisciplinary research process is a challenging task. It may be sensible to start the effort by concentrating on interdisciplinary knowledge generation and integration.

\section{Conclusions: potential benefits and challenges of transdiciplinary re- search}

Transdisciplinary research has the potential to support land and water management and better lead us towards sustainable development. Taking into account the concept of ecosystem services, transdisciplinary research can provide a systematic, comprehensive framework or approach for the definition and analysis of the problems concerning the balance of economic growth, ecological health, and human well-being. Through joint generation and integration of knowledge, transdisciplinary research can subsequently help derive knowledge-based strategies.

The potential benefits of transdisciplinary research include:

- Transdisciplinary research has the potential to integrate different types of knowledge (in our case this refers to knowledge about ecosystem services as well as land and water management that exists at different institutions in Xinjiang as well as to the research results of SuMaRiO researchers).

- Transdisciplinary research will facilitate cross- 
sectoral and cross-institutional knowledge exchange.

- By integration and communication, transdisciplinary research is likely to develop new system, target and transformation knowledge.

- Transdisciplinary research is likely to support the identification of actually implementable management options for sustainable development which take into account ecosystem services in a more explicit manner.

It is certainly challenging to embark on transdisciplinary research as even doing interdisciplinary research among scientists alone is not an easy task. This is caused by different research paradigms and approaches not only between natural and social sciences but also among natural sciences (Jakeman et al., 2006).

Getting involved in participatory research means that time and resources need to be invested to contribute to achieve the common good of transdisciplinary research. Stakeholders and even disciplinary scientists may perceive that a lot of additional time and resources are required for participation in transdisciplinary research process. They fear to be overstrained by activities beyond their respective institutional responsibilities. In this case, participatory process needs to be designed so that "stakeholder fatigue" can be avoided (Reed, 2008; Lamers et al., 2010).

Stakeholders and disciplinary scientists may also become reluctant to get involved in transdisciplinary research due to a lack of understanding of the principles and assumptions underlying transdisciplinary research. The concept and purposes of transdisciplinary research as well as why certain participatory methods are chosen under relevant conditions need to be clearly com-

\section{References}

Bammer G. 2005. Integration and implementation sciences: building a new specialization. Ecology and Society, 10(2): 6.

Beierle T C. 2002. The quality of stakeholder-based decisions. Risk Analysis, 22: 739-749.

Bishop P, Hines A, Collins T. 2007. The current state of scenario development: an overview of techniques. Foresight, 9(1): 5-25.

Bots P W G. 2007. Analysis of multi-actor policy contexts using perception graphs. In: Lin T Y. IEEE/WIC/ACM International Conference on Intelligent Agent Technology (IAT'07). Los Alamos: IEEE Press, 160-167.

Bromley J, Jackson N A, Clymer O J, et al. 2005. The use of Hugin ${ }^{\circledR}$ to develop Bayesian networks as an aid to integrated water resource municated to disciplinary scientists and stakeholders (Lamers et al., 2010). Moreover, expectations and needs of stakeholders also need to be taken into account and clarified at the initial stage of a participatory transdisciplinary process.

In transdisciplinary research, communication among stakeholders and scientists particularly in workshops must be facilitated in a skilful manner to avoid communication break-down. Misunderstandings can arise as a result of differences in thinking and language among scientists and stakeholders. Hence, language understandable for all should be used, while local socio-cultural and institutional setting should be recognized and considered. Both stakeholders and scientists getting involved in the process should be made aware of the evolutionary characteristic of transdisciplinary research. They need to be capable of adapting to changes and ready to face surprises that emerge during the process.

Last but not least, it has to be borne in mind that transdisciplinary research is not suitable for facilitating negotiation and conflict resolution among stakeholders. Rather, transdisciplinary research aims at helping stakeholders and society at large to identify actually implementable strategies for dealing with complex problems under uncertainty, like those generally occurring in land and water management.

\section{Acknowledgements}

This research is funded by the German Federal Ministry of Education and Research (BMBF).

planning. Environmental Modelling and Software, 20(2): 231-242.

Cain J D, Jinapala K, Makin I W, et al. 2003. Participatory decision support for agricultural management. a case study from Sri Lanka. Agricultural Systems, 76(2): 457-482.

CASS/ProClim. 1997. Researchers Visions. Research on Sustainability and Global Change. Visions in Science Policy by Swiss Researchers. ProClim-, Forum für Klima und Global Change, Schweizerische Akademie der Naturwissenschaften SANW, Bern.

Cronin K. 2008. Transdisciplinary research (TDR) and sustainability. [2011-08-21]. http://learningforsustainability.net/pubs/Transdisciplinary_Research_and_Sustainability.pdf.

Costanza R, d'Arge R, de Groot R, et al. 1997. The value of the world's 
ecosystem services and natural capital. Nature, 387: 253-260.

De Groot R S, Alkemade R, Braat L. 2010. Challenges in integrating the concept of ecosystem services and values in landscape planning, management and decision making. Ecological Complexity, 7(3): 260-272.

Döll C, Döll P. 2008. Modelling of problem perceptions and actions of actors in the field of mobile organic substances in surface waters. Salzburg geographical work, 43: 59-75.

Döll P, Hauschild M. 2002. Model-based scenarios of water use in two semi-arid Brazilian states. Regional Environmental Change, 2(4): $150-162$.

Döll P, Krol M. 2002. Integrated scenarios of regional development in two semi-arid states of Northeastern Brazil. Integrated Assessment, 3(4): 308-320.

EEA. 2001. Environmental Signals 2001. Copenhagen: European Environment Agency.

Gaiser T, Krol M, Frischkorn H, et al. 2003. Global Change and Regional Impacts. Berlin: Springer-Verlag.

Hare M, Deadman P. 2004. Further towards a taxonomy of agent-based simulation models in environmental management. Mathematics and Computers in Simulation, 64: 25-40.

Hirsch Hadorn G, Bradley D, Pohl C, et al. 2006. Implications of transdisciplinarity for sustainability research. Ecological Economics, 60: 119-128.

Huang X, Chen Y N, Ma J X, et al. 2010. Study on change in value of ecosystem service function of Tarim River. Acta Ecologica Sinica, 30: $67-75$.

Jahn T. 2008. Transdisciplinarity in research practice. In: Bergmann M, Schramm E. Transdiscplinary Research. Understanding and Assessing Integrative Research Processes. Frankfurt/New York: Campus, 21-37.

Jakeman A, Giupponi C, Karssenberg D, et al. 2006. Integrated management of water resources: concepts, approaches and challenges. In: Carraro C, Jakeman A, Karssenberg D, et al. Sustainable Management of Water Resources: An Integrated Approach. Cheltenham: Edward Elgar Publishing, 3-26.

Jiang L W, Tong Y F, Zhao Z J, et al. 2005. Water resources, land exploration and population dynamics in arid areas-the case of the Tarim River Basin in Xinjiang of China. Population and Environment, 26(6): 471-503.

Jiang Y M. 2009. Transdisciplinarity as a new form of research. Zhejiang Social Sciences, 1: 8-15.

Keil F, Stieß I. 2007. Knowing What We Don’t Know: Environmental Research as Societal Learning Process. GAIA 16/3, 193-199.

Lamers M, Ottow B, Francois G, et al. 2010. Beyond dry feet? Experiences from a participatory water management planning case in the Netherlands. Ecology and Society, 5(1): 14
Lu Z H, Zhao L X, Dai J. 2010. A study of water resource management in the Tarim Basin, Xinjiang. International Journal of Environmental Studies, 67(2): 245-255.

Luks F, Siebenhüner B. 2007. Transdisciplinarity for social learning? The contribution of the German socio-ecological research initiative to sustainability governance. Ecological Economics, 63: 418-426.

Lynam T, de Jong W, Shel D, et al. 2007. A review of tools for incorporating community knowledge, preferences, and values into decision making in natural resources management. Ecology and Society, 12(1): 5 .

Max-Neef M A. 2005. Foundations of transdisciplinarity. Ecological Economics, 53: 5-16.

Medema W, McIntosh B S, Jeffrey P J. 2008. From premise to practice: a critical assessment of integrated water resources management and adaptive management approaches in the water sector. Ecology and Society, 13(2): 29.

Millennium Ecosystem Assessment. 2005. Ecosystems and Human Well-being: Synthesis. Washington DC: Island Press.

Millington P. 2000. River basin management: its role in major water infrastructure projects. Thematic Review V.3. Cape Town: World Commission on Dams. [2011-09-22]. http://oldwww.wii.gov.in/eianew/eia/ dams \%20and\%20development/kbase/thematic/tr53main.pdf.

Mobjörk M. 2010. Consulting versus participatory transdisciplinarity: a refined classification of transdisciplinary research. Futures, 42: 866-873.

Oehlmann J, Schulte-Oehlmann U, Bachmann J, et al. 2006. Bisphenol A induces superfeminization in the ramshorn snail Marisa cornuarietis (Gastropoda: Prosobranchia) at environmentally relevant concentrations. Environmental Health Perspectives, 114(1): 127-133.

Pahl-Wostl C. 2005. Actor based analysis and modeling approaches. The Integrated Assessment Journal, 5(1): 97-118.

Petts G E, Nestler J, Kennedy R. 2006. Advancing science for water resources management. Hydrobiologia, 565: 277-288.

Pohl C, Hirsch Hadorn G. 2007. Principles for Designing Transdisciplinary Research. Oekom: Munich.

Pohl C, Hirsch Hadorn G. 2008. Methodological challenges of transdisciplinary research. Natures Sciences Societes, 16: 111-121.

Pohl C, von Kerkhoff L, Hirsch Hadorn G, et al. 2008. Core terms in transdisciplinary research. In: Hirsch Hadorn G, Hoffmann-Riem H, Biber-Klemm S, et al. Handbook of Transdisciplinary Research. Dordrecht: Springer, 427-432.

Pohl C. 2010. From transdisciplinarity to transdisciplinary research. Transdisciplinary Journal of Engineering \& Science, 1(1): 74-83.

Reed M S. 2008. Stakeholder participation for environmental management: a literature review. Biological Conservation, 141: 2417-2431.

Reyers B, Roux D J, Cowling R M. 2010. Conservation planning as a transdisciplinary process. Conservation Biology, 24(4): 957-965.

Schwartz P. 1998. The Art of the Long View: Planning for the Future in 
an Uncertain World. Chichester: John Wiley \& Son.

Seppelt R, Dormann C F, Eppink F V, et al. 2011a. A quantitative review of ecosystem service studies: approaches, shortcomings and the road ahead. Journal of Applied Ecology, 48: 630-636.

Seppelt R, Fath B, Burkhard B, et al. 2011b. Form follows function? Proposing a blueprint for ecosystem service assessments based on reviews and case studies. Journal of Ecological Indicators (Available online 7 October 2011).

Shen Y L, Lein H. 2005. Land and water resources management problems in Xinjiang Uygur Autonomous Region, China. Norsk Geografisk Tidsskrift—Norwegian Journal of Geography, 59(3): 237-245.

Steward-Koster B, Bunn S E, Mackay S J, et al. 2010. The use of Bayesian Networks to guide investments in flow and catchment restoration for impaired river ecosystems. Freshwater Biology, 55: 243-260.

Steventon J D. 2008. Conservation of marbled murrelets in British Columbia. In: Pourret O, Naim P, Marcot B. Bayesian Networks: A Practical Guide to Applications. Chichester: John Wiley and Sons, 127-148.

Stokols D. 2006. Toward a science of transdisciplinary action research. American Journal of Community Psychology, 38: 63-77.

Sultana P, Abeyasekera S. 2007. Effectiveness of participatory planning for community management of fisheries in Bangladesh. Journal of Environmental Management, 86: 201-213.

Tang D S, Deng M J. 2010. On the Management of Water Rights in the Tarim River Basin. Beijing: China Water Power Press.

TEEB. 2010. The Economics of Ecosystems and Biodiversity: Mainstreaming the Economics of Nature: A Synthesis of the Approach, Conclusions and Recommendations of TEEB. Mriehel (Malta): Progress Press.

Thevs N. 2011. Water scarcity and allocation in the Tarim Basin: Decision structures and adaptations on the local level. Journal of Current Chinese Affairs, 40: 113-137.

Thompson Klein J, Grossenbacher-Mansury W, Häberli R, et al. 2001. Transdisciplinarity: Joint Problem-solving Among Science, Technology and Society. Basel: Birkhäuser Verlag.
Tian Y L. 2008. Overview of the studies on ecosystem services. Journal of EMCC, 18: 46-50.

Titz A, Döll P. 2009. Actor modelling and its contribution to the development of integrative strategies for management of pharmaceuticals in drinking water. Social Science \& Medicine, 68: 672-681.

UNESCO. 2009. IWRM Guidelines at River Basin Level: Part 1 Principles. [2011-03-30]. http://www.unesco.org/water.

Vandermeulen V, Van Huylenbroeck G. 2008. Designing transdisciplinary research to support policy formulation for sustainable agricultural development. Ecological Economics, 67: 352-361.

Wiek A, Walter A I. 2009. A transdisciplinary approach for formalized integrated planning and decision-making in complex systems. European Journal of Operational Research, 197: 360-370.

Wiesmann U, Hirsch Hadorn G, Hoffmann-Riem H, et al. 2008. Enhancing transdisciplinary research: a synthesis in fifteen propositions. In: Hirsch Hadorn G, Hoffmann-Riem H, Biber-Klemm S, et al. Handbook of Transdisciplinary Research. Dordrecht: Springer, 433-441.

World Bank. 2006. Integrated River Basin Management: From Concepts to Good Practice. Case Study 3: Tarim River Basin and the Tarim Basin Water Resources Commission, People's Republic of China. Washington D.C.: The World Bank.

Wu Z T, Zhang H J, Krause C M, et al. 2010. Climate change and human activities: a case study in Xinjiang, China. Climatic Change, 99: 457-472.

Xu H L, Ye M, Song, Y D. 2005. The dynamic variation of water resources and its tendency in the Tarim River Basin. Journal of Geographical Sciences, 15(4): 467-474.

Xu H L, Ye M, Li J M. 2008. The water transfer effects on agricultural development in the lower Tarim River, Xinjiang of China. Agricultural Water Management, 95(1): 59-68.

Zhang B, Li W H, Xie G D. 2010a. Ecosystem services research in China: progress and perspective. Ecological Economics, 69: 1389-1395.

Zhang J B, Wu G H, Wang Q M, et al. 2010b. Restoring environmental flows and improving riparian ecosystem of Tarim River. Journal of Arid Land, 2(1): 43-50. 